Journal of Luminescence 11 (1975) 47-53

(c) North-Holland Publishing Company

\title{
LUMINESCENCE OF RARE EARTH VANADATE ASSOCIATES IN SULFATES
}

\author{
G. BLASSE and G.P.M. VAN DEN HEUVEL \\ Physical Laboratory, State University, Utrecht, The Netherlands
}

Received 30 May 1975

In some divalent metal sulfates $\left(\mathrm{CaSO}_{4}, \mathrm{PbSO}_{4}\right)$ the introduction of trivalent rare earth ions on the metal sites and pentavalent vanadium on the sulfur sites results in the formation of associates $\mathrm{V0}_{4}^{3-}-\mathrm{RE}^{3+}$. Energy transfer from the vanadate group to trivalent rare earth ions can be studied in these systems. It is shown that the transfer rate is temperature independent, but depends strongly on the choice of the host. In $\mathrm{CaSO}_{4}$ the transfer rate in the associate is estimated to be $\approx 10^{8} \mathrm{~s}^{-1}$, and in $\mathrm{PbSO}_{4} \approx 10^{4} \mathrm{~s}^{-1}$. The low transfer rate in $\mathrm{PbSO}_{4}: \mathrm{RE}, \mathrm{V}$ is ascribed to the influence of the $\mathrm{Pb}^{2+}$ ions on the charge distribution in the vanadate group.

\section{Introduction}

Energy transfer from the vanadate $\left(\mathrm{VO}_{4}^{3-}\right)$ group to trivalent rare earth ions $\left(\mathrm{RE}^{3+}\right)$ has been studied intensively in the host lattice $\mathrm{YVO}_{4}[1-3]$. Although excitation into the vanadate group is followed by $\mathrm{RE}^{3+}$ emission in many cases, the energy migration through the host lattice also plays an important role. At low temperatures this migration is hampered and no transfer to the $\mathrm{RE}^{3+}$ ions occurs. Recently, we have reported a system in which isolated associates consisting of $\mathrm{VO}_{4}^{3-}$ and $\mathrm{RE}^{3+}$ occur, namely $\mathrm{CaSO}_{4}$ with vanadium on sulfur sites and rare earth ions on calcium sites [4-6]. This system throws new light on the energy transfer process between the vanadate group and the trivalent rare earth ions. In $\mathrm{MgSO}_{4}$ the $\mathrm{VO}_{4}^{3-}$ and $\mathrm{RE}^{3+}$ are only partly associated and consequently their luminescence properties are different from those in $\mathrm{CaSO}_{4}$ [7].

This paper describes the results of a study of the luminescence of $\mathrm{VO}_{4}^{3-}$ and $\mathrm{RE}^{3+}$ in $\mathrm{PbSO}_{4}$ and compares these results with those for $\mathrm{VO}_{4}^{3-}$ and $\mathrm{RE}^{3+}$ in $\mathrm{CaSO}_{4}$ and $\mathrm{YVO}_{4}$. Some striking differences were observed. Further, $\mathrm{PbSO}_{4}$ was found to luminesce at room temperature.

\section{Experimental}

Samples were prepared as described in ref. [5] using $\mathrm{PbO}$ as starting material and 
$800^{\circ} \mathrm{C}$ as the final firing temperature. The RE and $\mathrm{V}$ concentrations were 0.3 at. $\%$. All samples were checked by X-ray analysis. Excitation and emission spectra were recorded down to $5 \mathrm{~K}$ on a Perkin-Elmer MPF-2A spectrofluorimeter. For more details see ref. [5].

\section{Results on $\mathrm{Ca}_{1-x} \mathrm{RE}_{x} \mathrm{~S}_{1-x} \mathrm{~V}_{x} \mathrm{O}_{4}$}

In order to facilitate a comparison between the results on $\mathrm{PbSO}_{4}$ samples with those on $\mathrm{CaSO}_{4}$ samples we summarize the more important $\mathrm{CaSO}_{4}$ results:

(a) $\mathrm{RE}^{3+}$ (on $\mathrm{Ca}^{2+}$ sites) and $\mathrm{VO}_{4}^{3-}$ (on $\mathrm{SO}_{4}^{2-}$ sites) occur solely as associates.

(b) If $\mathrm{RE}^{3+}=\mathrm{Y}^{3+}, \mathrm{Gd}^{3+}$ or $\mathrm{La}^{3+}$, excitation into the vanadate group (with absorption maximum at about $250 \mathrm{~nm}$ ) is followed by vanadate emission (with maximum at about $465 \mathrm{~nm}$ and decay time about $1 \mu \mathrm{s}$ ).

(c) If $\mathrm{RE}^{3+}=\mathrm{Pr}^{3+}, \mathrm{Sm}^{3+}, \mathrm{Eu}^{3+}, \mathrm{Tb}^{3+}, \mathrm{Dy}^{3+}$, excitation into the vanadate group is followed by efficient $\mathrm{RE}^{3+}$ emission, even at low temperatures. In $\mathrm{YVO}_{4}$ no energy transfer from $\mathrm{VO}_{4}^{3-}$ to $\mathrm{Pr}^{3+}$ or $\mathrm{Tb}^{3+}$ has been observed. This has been ascribed to radiationless decay via a charge-transfer state (see also ref. [8]). In $\mathrm{CaSO}_{4}$ the rate for energy transfer in the associate from $\mathrm{VO}_{4}^{3-}$ to $\mathrm{RE}^{3+}$ is estimated to be about $10^{8} \mathrm{~s}^{-1}$.

\section{Results on $\mathrm{Pb}_{1-x} \mathrm{RE}_{x} \mathrm{~S}_{1-x} \mathrm{~V}_{x} \mathrm{O}_{4}$}

Unactivated $\mathrm{PbSO}_{4}$ shows, at room temperature and lower temperatures, a broad emission band peaking at about $360 \mathrm{~nm}$ if excited with radiation of $\lambda<225 \mathrm{~nm}$ (shown in fig. 1 for a doped sample). Diffuse reflection spectra show that the optical

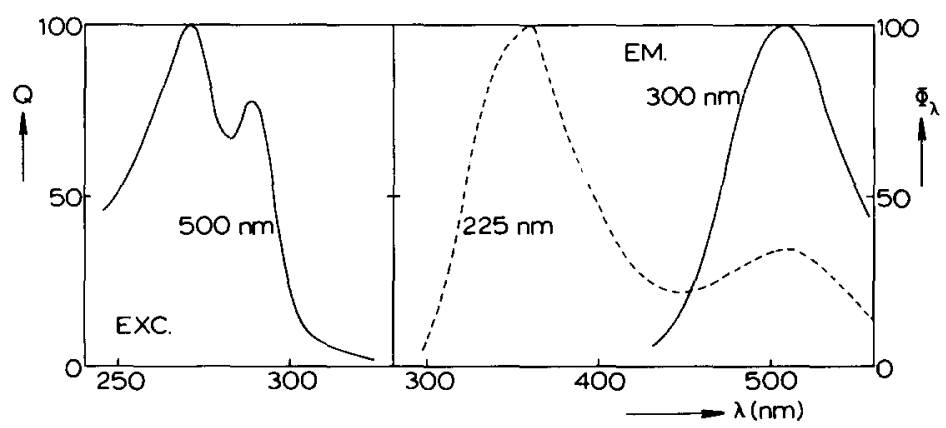

Fig. 1. Relative excitation spectrum of the $500 \mathrm{~nm}$ emission of $\mathrm{Pb}_{0.997} \mathrm{La}_{0.003} \mathrm{~S}_{0.997} \mathrm{~V}_{0.003} \mathrm{O}_{4}$ at $5 \mathrm{~K}$ (left-hand side: $Q$ gives the relative quantum output) and spectral energy distribution of the emission at $5 \mathrm{~K}$ of this sample (right-hand side: $\Phi_{\lambda}$ gives the spectral radiant power per constant wavelength interval in arbitrary units; drawn line for $300 \mathrm{~nm}$ excitation; broken line for $225 \mathrm{~nm}$ excitation). 


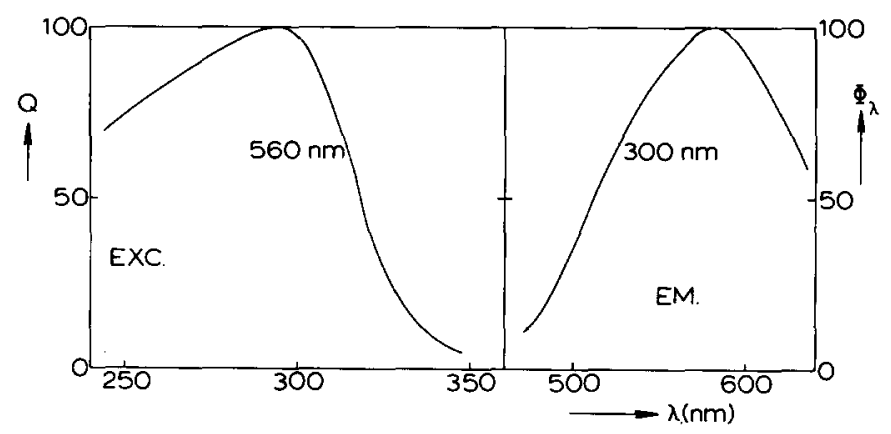

Fig. 2. Relative excitation spectrum of the $560 \mathrm{~nm}$ emission of $\mathrm{PbSO}_{4}-\mathrm{V}(0.003)$ at $5 \mathrm{~K}$ (left-hand side) and spectral energy distribution of the emission at $5 \mathrm{~K}$ of this sample (right-hand side: 300 $\mathrm{nm}$ exictation).

absorption edge is at about $225 \mathrm{~nm}$ at $300 \mathrm{~K}$. The same emission and excitation bands were found in $\mathrm{Ca}_{1-x} \mathrm{~Pb}_{x} \mathrm{SO}_{4}$ and $\mathrm{Ba}_{1-x} \mathrm{~Pb}_{x} \mathrm{SO}_{4}$ ( $x$ down to 0.01 ), so that they are ascribed to intrinsic $\mathrm{Pb}^{2+}$ transitions. We observed direct energy transfer from the $\mathrm{Pb}^{2+}$ ions to $\mathrm{RE}^{3+}$ in $\mathrm{Pb}_{1-x} \mathrm{RE}_{x} \mathrm{~S}_{1-x} \mathrm{~V}_{x} \mathrm{O}_{4}$. Energy transfer from $\mathrm{Pb}^{2+}$ to the vanadate group also occurred. These transfers will be discussed elsewhere.

In $\mathrm{PbSO}_{4}: \mathrm{V}, \mathrm{La}$ and $\mathrm{PbSO}_{4}: \mathrm{V}, \mathrm{Y}$ we observed a greenish vanadate emission peaking at about $510 \mathrm{~nm}$ with excitation bands peaking at about 290 and $270 \mathrm{~nm}$ (see fig. 1). The quenching temperature is situated above room temperature (about $350 \mathrm{~K}$ ). The decay time of this emission is much longer than in $\mathrm{CaSO}_{4}$, namely $35 \mu \mathrm{s}$. In $\mathrm{PbSO}_{4}: \mathrm{V}$ (without $\mathrm{RE}$ ), however, the vanadate emission and excitation bands are situated at considerably longer wavelengths, namely 580 and $300 \mathrm{~nm}$, respectively (fig. 2). This difference between the $\mathrm{RE}^{3+}{ }_{\text {-compensated and the uncompensated }}$ sample was also observed for $\mathrm{CaSO}_{4}$ and is strong evidence for the presence of $\mathrm{VO}_{4}^{3-}-\mathrm{RE}^{3+}$ associates in $\mathrm{PbSO}_{4}$.

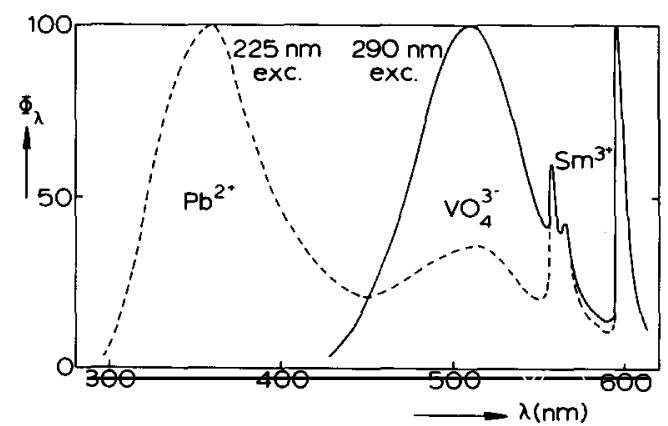

Fig. 3. Spectral energy distribution of the emission of $\mathrm{Pb}_{0.997} \mathrm{Sm}_{0.003} \mathrm{~S}_{0.997} \mathrm{~V}_{0.003} \mathrm{O}_{4}$ at $5 \mathrm{~K}$ for $225 \mathrm{~nm}$ excitation (broken line) and $290 \mathrm{~nm}$ excitation (drawn line). 
Table 1

Ratio of $\mathrm{RE}^{3+}$ quantum efficiency to total quantum efficiency for samples $\mathrm{Pb}_{1-x} \mathrm{RE}_{x} \mathrm{~S}_{1-x} \mathrm{~V}_{x} \mathrm{O}_{4}$ $(x=0.003)$ for vanadate excitation.

RE

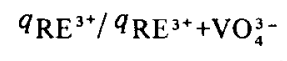

$5 \mathrm{~K} \quad 300 \mathrm{~K}$

\begin{tabular}{lll}
\hline $\mathrm{Pr}^{3+}$ & 0.08 & 0.10 \\
$\mathrm{Sm}^{3+}$ & 0.09 & 0.10 \\
$\left.\mathrm{Eu}^{3+\mathrm{a}}\right)$ & 0.1 & 0.1 \\
$\mathrm{~Tb}^{3+\mathrm{b})}$ & 0.5 & 0.75 \\
$\mathrm{Dy}^{3+}$ & 0.15 & 0.15
\end{tabular}

a) Samples may contain Eú partly in the divalent state.

b) Excitation may be partly in $4 \mathrm{f}-5 \mathrm{~d}$ of $\mathrm{Tb}^{3+}$.

Table 2

Energy transfer probability for associates studied in $\mathrm{YVO}_{4}, \mathrm{CaSO}_{4}, \mathrm{PbSO}_{4}$ (-: no transfer, + : efficient transfer, 0 : transfer probability low to medium).

\begin{tabular}{llll}
\hline & $\mathrm{YVO}_{4}$ & $\mathrm{CaSO}_{4}$ & $\mathrm{PbSO}_{4}$ \\
\hline $\mathrm{VO}_{4}^{3-} \rightarrow \mathrm{Pr}^{3+}+$ & + & 0 \\
$\mathrm{VO}_{4}^{3-} \rightarrow \mathrm{Sm}^{3+}+$ & + & 0 \\
$\mathrm{VO}_{4}^{3-} \rightarrow \mathrm{Eu}^{3+}+$ & + & 0 \\
$\mathrm{VO}_{4}^{3-} \rightarrow \mathrm{Tb}^{3+}-$ & + & 0 \\
$\mathrm{VO}_{4}^{3-} \rightarrow \mathrm{Dy}^{3+}+$ & + & 0 \\
\hline
\end{tabular}

We introduced in $\mathrm{PbSO}_{4}$ those rare earth ions that showed efficient emission in $\mathrm{CaSO}_{4}$, namely $\mathrm{Pr}^{3+}, \mathrm{Sm}^{3+}, \mathrm{Eu}^{3+}, \mathrm{Tb}^{3+}$ and $\mathrm{Dy}^{3+}$. Remarkably, excitation into the vanadate absorption band did not result in efficient $\mathrm{RE}^{3+}$ emission: we observed mainly vanadate emission. In table 1 we have tabulated the ratio of the $\mathrm{RE}^{3+}$ quantum efficiency and the total emission quantum efficiency for excitation into the vanadate group. Fig. 3 shows the emission spectrum of $\mathrm{Pb}_{1-x} \mathrm{Sm}_{x} \mathrm{~S}_{1-x} \mathrm{~V}_{x} \mathrm{O}_{4}$ for excitation into the vanadate excitation band. We note that excitation into the $\mathrm{Pb}^{2+}$ ions $(225 \mathrm{~nm})$ result in a higher ratio of $\mathrm{RE}^{3+}$ and vanadate emission than into the vanadate group itself.

In table 2 we have given a qualitative survey of the efficiency of energy transfer from the vanadate group to $\mathrm{RE}^{3+}$ ions in $\mathrm{YVO}_{4}, \mathrm{CaSO}_{4}$ and $\mathrm{PbSO}_{4}$. It is evident that the influence of the host lattice on this transfer efficiency is drastic. 


\section{Discussion}

Energy transfer from the vanadate group to the trivalent rare earths is now considered to occur via exchange interaction with a relatively short critical distance. Consequently, the transfer probability is mainly determined by two factors, namely the spectral overlap and an exchange integral [9]. The broad vanadate emission usually overlaps one or more $f-f$ absorption lines, so that transfer occurs, albeit with a relatively slow rate.

From this model it does not become clear why there is no transfer from the vanadate group to $\mathrm{Tb}^{3+}$ and $\mathrm{Pr}^{3+}$ (in $\mathrm{YVO}_{4}$ and $\mathrm{YPO}_{4}$ ) and why at low temperatures there is no energy transfer to the lanthanides in $\mathrm{YVO}_{4}$. In $\mathrm{CaSO}_{4}: \mathrm{V}, \mathrm{RE}$, however, there is efficient transfer to $\mathrm{Tb}^{3+}$ and $\mathrm{Pr}^{3+}$. This has been explained by the presence of effective charges on the $\mathrm{RE}^{3+}$ ions (on $\mathrm{Ca}^{2+}$ sites) and the $\mathrm{V}^{5+}$ ions (on $\mathrm{S}^{6+}$ sites) $[5,6]$ which displace the interfering charge-transfer state $\mathrm{V}^{4+}-\mathrm{RE}^{4+}$ to higher energies. Further, the study on the $\mathrm{CaSO}_{4}: \mathrm{V}, \mathrm{RE}$ systems shows that the transfer is independent of temperature as is to be expected from theory. Temperature-dependent transfer phenomena in $\mathrm{YVO}_{4}$ are due to the temperature dependence of the vanadatevanadate energy transfer which is hampered at low temperatures.

From the radiant decay time of the vanadate emission in $\mathrm{CaSO}_{4}: \mathrm{V}, \mathrm{Y}(\approx 1 \mu \mathrm{s})$ the rate of energy transfer from the vanadate group to the rare earth ions can be estimated as about $10^{8} \mathrm{~s}^{-1}$.

We now turn to the results for the $\mathrm{PbSO}_{4}: \mathrm{V}, \mathrm{RE}$ system and consider first $\mathrm{RE}=\mathrm{La}$ (or $\mathrm{Y}$ ), i.e. non-luminescing $\mathrm{RE}$ ions. The vanadate emission in these systems differs from that in uncompensated $\mathrm{PbSO}_{4}: \mathrm{V}$ (see figs. 1 and 2) which we consider as strong evidence for association of $\mathrm{V}^{5+}$ and $\mathrm{RE}^{3+}$ as in $\mathrm{CaSO}_{4}$ where the situation is similar. This is sustained by the larger halfwidth of the emission band in the case of the uncompensated $\mathrm{PbSO}_{4}-\mathrm{V}$ sample (compare figs. 1 and 2).

If $\mathrm{PbSO}_{4}: \mathrm{V}, \mathrm{La}$ (or $\mathrm{Y}$ ) is excited with $\approx 220 \mathrm{~nm}$ radiation, mainly $360 \mathrm{~nm}$ emission is observed. This is considered to be the well-known ${ }^{3} \mathrm{P}_{1}-{ }^{1} \mathrm{~S}_{0}$ emission of $\mathrm{Pb}^{2+}$ which will not be considered here. Excitation with radiation with $\lambda$ between 260 and $300 \mathrm{~nm}$ results in a quite different emission peaking at $510 \mathrm{~nm}$. We assume that this is the vanadate emission (it is absent for pure $\mathrm{PbSO}_{4}$ ). In $\mathrm{CaSO}_{4}$ this emission peaks at shorter wavelength, namely $465 \mathrm{~nm}$. In addition the radiant decay time of the vanadate emission in $\mathrm{PbSO}_{4}: \mathrm{V}, \mathrm{La}$ is much longer than in $\mathrm{CaSO}_{4}: \mathrm{V}, \mathrm{Y}$.

We explain this difference by the assumption that in $\mathrm{CaSO}_{4}$ the vanadate absorption and emission is a pure charge-transfer transition within the vanadate group [10], whereas in $\mathrm{PbSO}_{4}$ it has much more the character of a metal-metal $\left(\mathrm{Pb}^{2+}-\mathrm{V}^{5+}\right)$ charge-transfer transition [11]. Ample evidence for transitions of this type have been put forward for $\mathrm{Bi}^{3+}-\mathrm{V}^{5+}$ in $\mathrm{YPO}_{4}[11,12]$ and for $\mathrm{Pb}^{2+}-\mathrm{W}^{6+}\left(\mathrm{Mo}^{6+}\right)$ in $\mathrm{PbWO}_{4}$ and $\mathrm{PbMoO}_{4}[13,14]$. This explains at the same time why the transitions are at lower energies in $\mathrm{PbSO}_{4}$ than in $\mathrm{CaSSO}_{4}$ and why the radiant decay time in $\mathrm{PbSO}_{4}$ is much logner (less wave-function overlap) than in $\mathrm{CaSO}_{4}$.

It might be argued that the crystal structure of $\mathrm{PbSO}_{4}$ (baryte) is different from 
$\mathrm{CaSO}_{4}$ (anhydrite) and that this might cause the difference in the vanadate emissions. In $\mathrm{BaSO}_{4}: \mathrm{V}, \mathrm{Y}$, however, the vanadate luminescence is very much like that in $\mathrm{CaSO}_{4}: \mathrm{V}, \mathrm{Y}$ [7], although $\mathrm{BaSO}_{4}$ and $\mathrm{PbSO}_{4}$ are isomorphous.

Note in passing that metal-metal charge-transfer transitions of this type often have a relatively high quenching temperature of their luminescence, e.g. $\mathrm{CaWO}_{4}: \mathrm{Pb}$ [15] and $\mathrm{PbSO}_{4}: \mathrm{V}, \mathrm{La}(350 \mathrm{~K}$, whereas the $\mathrm{Ca}$ and $\mathrm{Ba}$ sample have 200 and $150 \mathrm{~K}$, respectively).

We now turn to samples $\mathrm{PbSO}_{4}$ : $\mathrm{V}, \mathrm{RE}$ with luminescing $\mathrm{RE}$ ions. From table 1 it is obvious that the transfer rate is so low that excitation into the vanadate group is followed by mainly vanadate emission (see fig. 3). From the radiant decay time of the emission of $\mathrm{PbSO}_{4}: \mathrm{V}, \mathrm{La}(35 \mu \mathrm{s})$ the transfer rate in the associate can be estimated as about $10^{3}-10^{4} \mathrm{~s}^{-1}$. This is a factor $10^{4}$ less than in the $\mathrm{CaSO}_{4}$ system.

It seems improbable that the spectral overlap integral is responsible for this drastic reduction. Although the vanadate emission in $\mathrm{PbSO}_{4}$ is at longer wavelength than in $\mathrm{CaSO}_{4}$ there is always overlap with levels from the $4 \mathrm{f}^{n}$ configuration of the rare earth ions. This means that the exchange integral in the expression for the transfer rate must be responsible for the large difference in transfer rate in $\mathrm{PbSO}_{4}$ and $\mathrm{CaSO}_{4}$. An obvious explanation is that the wave-function overlap of a pure-vanadate excited charge transfer state (involving $2 \mathrm{pO}^{2-}$ and $3 \mathrm{dV}^{5+}$ wave functions) and the $4 \mathrm{f}^{n}$ state will be larger than the overlap in the case of a $\mathrm{Pb}^{2+}-\mathrm{VO}_{4}^{3-}$ exicted chargetransfer state (involving $6 \mathrm{~s} \mathrm{~Pb}^{2+}$ and $3 \mathrm{~d} \mathrm{~V}^{5+}$ wavefunctions) and a $4 \mathrm{f}^{n}$ state. Overlap with the $4 \mathrm{f}$ orbitals will occur mainly via the oxygen anions ("super-exchange interaction"); these anions play a more important role in $\mathrm{CaSO}_{4}$ than in $\mathrm{PbSO}_{4}$. This argument runs parallel with an explanation previously given to explain the low energy transfer rate from $\mathrm{VO}_{4}^{3-}$ to $\mathrm{Eu}^{3+}$ in $\mathrm{InVO}_{4}$ [12].

A more qunatitative elucidation seems difficult at the moment. Nevertheless it is striking and unexpected to find how the rate of transfer from $\mathrm{VO}_{4}^{3-}$ to $\mathrm{RE}^{3+}$ is influenced by the choice of the host lattice.

Finally, the variation of the transfer rate in $\mathrm{PbSO}_{4}-\mathrm{V}, \mathrm{RE}$ with the nature of $\mathrm{RE}$ is intriguing. Two effects may play a role here:

(a) if the fourth ionization potential of the RE is relatively low it will be easier to admix into the $\mathrm{Pb}^{2+}-\mathrm{VO}_{4}^{3-}$ excited charge-transfer state;

(b) the $\mathrm{RE}^{3+}$ ions are considerably smaller than $\mathrm{Pb}^{2+}[16]$, probably the 12-coordinated site of $\mathrm{Pb}^{2+}$ in the baryte structure is too large for them, so that they are displaced from the centre of the $\mathrm{Pb}^{2+}$ site to the $\mathrm{V}^{5+}$ ion. This effect will be more important for the smaller $\mathrm{RE}^{3+}$ ions and results in a larger wave-function overlap.

The former effect favors transfer to $\mathrm{Pr}^{3+}$ and $\mathrm{Tb}^{3+}$, the latter $\mathrm{Tb}^{3+}$ and $\mathrm{Dy}{ }^{3+}$. Our results (table 1) do not contradict such an explanation. It should be realized that the $\mathrm{Tb}^{3+}$ results may be influenced by the fact that the $\mathrm{VO}_{4}^{3-}$ excitation band may overlap the $4 \mathrm{f}--5 \mathrm{~d}$ excitation band of $\mathrm{Tb}^{3+}$. Perhaps this is also the reason why the temperature dependence (table 1 ) in the case of $\mathrm{Tb}^{3+}$ is anomalous. 


\section{References}

[1] A.K. Levine and F.C. Palilla, Electrochem. Techn. 4 (1966) 16.

[2] F.C. Palilla, Electrochem. Techn. 6 (1968) 39.

[3] G. Blasse and A. Bril, J. Electrochem. Soc. 115 (1968) 1067.

[4] W. Hordijk and G. Blasse, J. Luminescence 6 (1973) 137.

[5] W.T. Draai and G. Blasse, Phys. Stat. Sol. (a) 21 (1974) 569.

[6] W.T. Draai and G. Blasse, Chem. Phys. Letters 25 (1974) 167.

[7] G. Blasse and H.G. Pietersen, J. Solid State Chem. 11 (1974) 148.

[8] R.G. DeLosh, T.Y. Tien, E.F. Gibbons, P.J. Zacmanides and H.L. Stadler, J. Chem. Phys. $53(1970) 681$.

[9] D.L. Dexter, J. Chem. Phys. 21 (1953) 836.

[10] C.K. Jorgensen, Absroption spectra and chemical bonding in complexes (Pergamon Press, London, 1962).

[11] G. Blasse and A. Bril, J. Chem. Phys. 48 (1968) 217.

[12] G. Blasse and A. Bril, J. Chem. Phys. 50 (1969) 2974; Philips Res. Rept. 23 (1968) 344.

[13] W. van Loo, Thesis, Utrecht (1974); Phys. Stat. Sol. (a) 27 (1975) 565; 28 (1975) 227.

[14] G. Blasse and A. Bril, Philips Res. Rept. 24 (1969) 275.

[15] F.A. Kröger, Some aspects of the luminescence of solids (Elsevier, Amsterdam, 1948).

[16] R.D. Shanon and C.T. Prewitt, Acta Cryst. B25 (1969) 925. 